\title{
Respuesta de cilantro (Coriandrum sativum L.) a la luz LED azul y roja
}

\author{
Coriander (Coriandrum sativum L.) response to blue and red LED light
}

\author{
J.E. Mendoza-Paredes ${ }^{1 *}$, A.M. Castillo-González' , L.A. Valdéz-Aguilar², E. Avitia-García' y M.R. García-Mateos' \\ Departamento de Fitotecnia, Universidad Autónoma Chapingo, Texcoco de Mora, Estado de México, México. \\ 2 Departamento de Horticultura, Universidad Autónoma Agraria Antonio Narro, Saltillo, Coahuila, México.
}

\section{RESUMEN}

El cilantro es una especie ampliamente aceptada debido a usos culinarios y propiedades medicinales. Este cultivo podría desarrollarse en ambiente controlado con iluminación LED y permitiría tener una producción continua, con un aumento exponencial de rendimiento y estar libre de plagas y enfermedades. Hay poca investigación sobre la respuesta del cilantro en tales condiciones. Los objetivos de este estudio fueron evaluar el efecto de cinco proporciones de luz LED azul:roja sobre parámetros de crecimiento en planta, concentración de pigmentos fotosintéticos y nutrimental en la parte aérea de cilantro 'Gladiador' bajo condiciones controladas de crecimiento. Los resultados se ajustaron a una regresión polinomial de tercer grado. Una proporción de luz azul (A) y roja (R) de A37.7 \%:R62.3 \% promovió los parámetros de crecimiento y concentración de pigmentos fotosintéticos, mientras que una proporción A57.7 \%:R42.3 $\%$ promovió la concentración nutrimental en la parte aérea de cilantro. Lo anterior permite deducir que para una posible producción comercial de cilantro, en condiciones de ambiente controlado, la mejor proporción de luz azul y roja es de A37.7 \%:R62.3 \% ya que se promueve el crecimiento y por lo tanto el rendimiento comercial.

Palabras clave: ambiente controlado, hidroponía, pigmentos fotosintéticos, macronutrimentos, micronutrimentos

\section{ABSTRACT}

Coriander is a widely accepted species due to its culinary uses and medicinal properties. This crop could be developed in a controlled environment with LED lighting and would allow continuous production, with an exponential increase in yield, and free of pests and diseases. There is little research about the response of coriander under such conditions. The objectives of this study were to evaluate the effects of five ratios of blue:red LED light on growth parameters, photosynthetic pigments and nutriments concentration in the aerial part of coriander 'Gladiador' under controlled growth conditions. The results were adjusted to a third-degree polynomial regression. A A37.7 \%: R62.3 \% blue (A) and red (R) light ratio promoted growth parameters and photosynthetic pigments concentration, while a A57.7 \%: R42.3 \% ratio promoted nutrient concentration in the aerial coriander part. This allows us to deduce that for a possible

\footnotetext{
*Autor para correspondencia: Jorge Enrique Mendoza Paredes Correo electrónico: jmendozaparedes@hotmail.com
}

commercial production of coriander, under controlled environment conditions, the best blue and red light ratio is A37.7 $\%:$ R62.3 \%, since growth and therefore commercial yield are promoted.

Key words: controlled environment, hydroponic, photosynthetic pigments, macronutrient, micronutrient

\section{INTRODUCCIÓN}

El cilantro es nativo del sur de Europa y del oeste de la región Mediterránea (Wei et al., 2019), se cultiva extensamente en países de Latinoamérica, Europa central, Asia, África y Australia (Laribi et al., 2015; Mahendra y Bisht, 2011). Se ha usado por diversas culturas del mundo en cuestiones culinarias y en medicina tradicional (Prachayasittikul et al., 2018; Wei et al., 2019), tiene actividad antimicrobiana, antioxidante, antiinflamatoria entre otras (Laribi et al., 2015).

La agricultura vertical, es un sistema de producción agrícola cerrado donde se pueden controlar, establecer y monitorear, todas las variables ambientales, nutrición y de riego necesarias en una planta, el sistema está aislado del ambiente circundante mediante el uso de estructuras sólidas y herméticas, junto con el uso de una fuente de iluminación LED que sustituye a la luz solar y equipo electrónico-mecánico junto con software especializado que permite controlar el sistema totalmente, además, este sistema usa anaqueles para cultivar de manera vertical, con lo cual, se logra tener una producción continua anual, cultivos libres de plagas y enfermedades y un aumento de producción basado en el número de niveles que se puedan utilizar (Kozai y Niu, 2016). Con esta técnica de cultivo puede ser una alternativa para aminorar los efectos del estrés salino en suelos que afectan la productividad de distintos cultivos (Clarenc-Aarland et al., 2020), disminuir el uso y la resistencia de pesticidas (Alvarez-Carvajal et al., 2020) y una forma de producir plantas para consumo libres de contaminación con metales pesados (Márquez-Reyes et al., 2020).

La luz genera tres señales, que tienen un efecto en el aparato fotosintético, en procesos bioquímicos dependientes de luz y fotorreceptores, estos en conjunto generan al final a través de una cascada de procesos fisiológicos, genéticos y bioquímicos, el crecimiento y desarrollo de la planta (Berkovich et al., 2017). La planta aprovecha principalmente la luz dentro del intervalo del espectro electromagnético que 
abarca desde los 400 a 700 nm llamada radiación fotosintéticamente activa (RFA) (Blankenship, 2014), sin embargo, estas absorben más activa y eficientemente la luz en las regiones del color azul (400-500 nm) y color rojo (600-700 nm), las cuales corresponden a los picos de máxima absorción de luz de los de los fotorreceptores (fitocromos, criptocromos, fototropinas y proteínas ZEITLUPE) y de los pigmentos fotosintéticos (clorofila a, b y carotenoides) que forman parte del aparato fotosintético (Huché-Thélier et al., 2016). La tecnología de iluminación LED permite, dado sus espectros de emisión y pico de longitud de onda, coincidir con las regiones de luz azul y roja, con lo cual se estimula el proceso de fotosíntesis volviéndose más eficiente de manera global (Viršilè et al., 2017).

Dada las dos diferentes regiones de luz azul y roja, debido su importancia bioquímica y energética, se pueden evaluar cuál es la mejor proporción de luz azul y roja, en la cual una especie tiene su mejor desarrollo en general, a partir de estos dos colores de luz (Berkovich et al., 2017).

Debido a que el cilantro es una planta de porte pequeño, con ciclo corto de crecimiento y cuenta con diversos usos, propiedades y consumida en varias regiones del mundo, es un cultivo idóneo para cultivarse en agricultura vertical con iluminación LED (Kozai y Niu, 2016).

El cilantro tiene muy poca investigación en estas condiciones de crecimiento; Naznin et al. (2016) encontraron la mayor altura de planta con una relación de luz roja (R) y azul (A) R100:A0, el mayor número de hojas, peso fresco y seco con R10:A1 y la capacidad antioxidante con R5:A1. Nguyen et al. (2019), reportaron la mayor acumulación de biomasa de planta y contenido de agua en la hoja y el tallo a una temperatura de raíz de $25^{\circ} \mathrm{C}$ y $300 \mu \mathrm{mol} \mathrm{m} \mathrm{s}^{-1}$ con una combinación de luz (rojo+blanco+rojo lejano).

El objetivo del presente estudio fue evaluar el efecto de diferentes proporciones de luz LED roja y azul en variables del crecimiento, concentración de pigmentos fotosintéticos y contenido nutrimental en la parte aérea de cilantro. Esta investigación podrá ampliar el conocimiento que se tiene del cultivo del cilantro en condiciones controladas de crecimiento con iluminación LED para su posibilidad de aplicación a nivel comercial en agricultura vertical en un futuro.

\section{MATERIALES Y MÉTODOS Producción de planta}

Se utilizaron semillas de cilantro 'Gladiador' de Sakata Seed de México, las cuales se sembraron a una profundidad de $0.5 \mathrm{~cm}$ en turba rubia (Pro mix $\left.{ }^{\circledast}, \mathrm{CAN}\right)(\mathrm{pH}$ de $5.5 \mathrm{y}$ CE 0.75 en dS $\mathrm{m}^{-1}$ ) en contenedores de plástico rígido con un volumen de $500 \mathrm{~mL}$ (15 semillas por maceta). Una vez sembradas se colocaron en invernadero y fueron regadas con agua potable ( $\mathrm{pH} 7.1$ y CE $\left.0.42 \mathrm{dS} \mathrm{m}^{-1}\right)$. La temperatura ambiental promedio fue: día $21.1 \pm 0.1{ }^{\circ} \mathrm{C} /$ noche $14.2 \pm 0.2{ }^{\circ} \mathrm{C}$ y la humedad relativa: día $62.1 \pm 0.2 \% /$ noche $83.3 \pm 0.3 \%$, que se registró con un datalogger (Extech instruments ${ }^{\circledR}$ modelo RH10, USA). El periodo de emergencia duró 6 días después de la siembra y a los 9 días se colocaron en una cámara de crecimiento para iniciar los tratamientos con luz.
Tabla 1. Propiedades físicas de los tratamientos con diferentes proporciones de luz LED azul y roja aplicadas en cilantro 'Gladiador' cultivado bajo condiciones controladas.

Table 1. Physical properties of treatments with different blue and red LED light ratios applied on coriander 'Gladiador' grown under controlled conditions.

\begin{tabular}{|c|c|c|c|c|c|}
\hline \multicolumn{6}{|c|}{ Tratamientos } \\
\hline & AO & A37.7 & A57.7 & A74.2 & A100 \\
\hline PrA & AO \% & A $37.7 \%$ & A57.7 \% & A74.2 \% & A $100 \%$ \\
\hline PrR & R100 \% & R62.3 \% & R42.3 \% & R25.8 \% & Ro $\%$ \\
\hline Dtot & $308.9 \pm 8.7 a^{x}$ & $309.5 \pm 7.9 a$ & $305.3 \pm 6.0 \mathrm{a}$ & $308.8 \pm 5.4 a$ & $305.7 \pm 6.3 a$ \\
\hline LID & $16.7 \pm 0.5 \mathrm{a}$ & $16.7 \pm 0.4 a$ & $16.5 \pm 0.3 a$ & $16.7 \pm 0.3 a$ & $16.5 \pm 0.3 a$ \\
\hline$\lambda A$ & - & $457 \pm 0 b$ & $457 \pm 0 \mathrm{a}$ & $457 \pm 0 b$ & $457 \pm 0 b$ \\
\hline \multirow{2}{*}{$\mathrm{I} \lambda \mathrm{A}$} & - & $421 \pm 0 a$ & $418 \pm 0 b$ & $416 \pm 0 c$ & $414 \pm 0 d$ \\
\hline & - & $510 \pm 1 d$ & $516 \pm 0 c$ & $518 \pm 0 b$ & $521 \pm 0 a$ \\
\hline$\% D A$ & - & $37.7 \pm 0.9 d$ & $57.7 \pm 0.6 c$ & $74.2 \pm 0.6 b$ & $100.0 \pm 0.0 \mathrm{a}$ \\
\hline$\lambda R$ & $636 \pm 0 \mathrm{~b}$ & $635 \pm 0 c$ & $637 \pm 0 \mathrm{a}$ & $636 \pm 0 b$ & - \\
\hline \multirow{2}{*}{$\mid \lambda R$} & $594 \pm 0 c$ & $594 \pm 0 c$ & $597 \pm 0 \mathrm{~b}$ & $599 \pm 0 a$ & - \\
\hline & $674 \pm 0 \mathrm{a}$ & $671 \pm 0 b$ & $670 \pm 0 c$ & $665 \pm 0 d$ & - \\
\hline$\% \mathrm{DR}$ & $100.0 \pm 0.0 \mathrm{a}$ & $62.3 \pm 0.9 b$ & $42.3 \pm 0.6 c$ & $25.8 \pm 0.6 d$ & - \\
\hline
\end{tabular}

'Medias $\pm D E$ con letras iguales en las filas son estadísticamente iguales (Tukey, $\mathrm{P} \leq 0.05$ ). A= Luz LED azul; R= Luz LED roja; PrA= Proporción azul; PrR= Proporción rojo; Dtot= Densidad de flujo de fotones fotosintéticos total de tratamiento $\left(\mu \mathrm{mol} \mathrm{m}{ }^{-2} \mathrm{~s}^{-1}\right)$; LID= Luz integral diaria $\left(\mathrm{mol} \mathrm{m}^{-2} \mathrm{~d}^{-1}\right)$; $\lambda A=$ Pico de longitud de onda $(\mathrm{nm})$ color azul; $\mid \lambda A=$ Intervalo de longitud de onda (nm) color azul; \% DA= Porcentaje de densidad de flujo de fotones fotosintéticos de luz azul (\%); $\lambda \mathrm{R}=$ Pico de longitud de onda $(\mathrm{nm})$ color rojo; $\mid \lambda R=$ Intervalo de longitud de onda color rojo $(\mathrm{nm}) ; \% \mathrm{DR}=$ Porcentaje de densidad de flujo de fotones fotosintéticos de luz roja (\%).

\section{Cámara y gabinetes de crecimiento}

Se adaptó una cámara de crecimiento con medidas interiores de $2.76 \mathrm{~m} \times 2.76 \mathrm{~m} \times 1.90 \mathrm{~m}$ (ancho, largo y altura), las modificaciones internas de la cámara de crecimiento se basó en el diseño de Katagiri et al. (2015), con las cuales se logró regular la temperatura ambiental y la humedad relativa a través de un aire acondicionado portátil $\left(\mathrm{LG}^{\circledR} \mathrm{mo}^{-}\right.$ delo LP1017WSR 10200 BTU, KOR) y un deshumidificador (Whirlpool ${ }^{\circledast}$ modelo WAD200 5Q 20L/24 h, USA), los que se colocaron dentro de la cámara de crecimiento. Se diseñaron cinco gabinetes de crecimiento con la finalidad de mantener aislados los tratamientos de luz. Éstos se construyeron a partir de un anaquel metálico $(0.3 \mathrm{~m}$ de ancho $\times 0.85 \mathrm{~m}$ de largo $x 1.00 \mathrm{~m}$ de altura), al cual se le añadieron paredes de placas de unicel de $2 \mathrm{~cm}$ de grosor forradas con papel aluminio, con la finalidad de tener un máximo de reflexión de la luz en su interior.

\section{Tratamientos con diferentes proporciones de luz LED roja y azul}

Las luminarias que se utilizaron fueron hechas a mano, compuestas por perfiles de aluminio de $5 \mathrm{~cm} \times 85 \mathrm{~cm}$ (ancho $x$ largo) en donde se anclaron los focos LED (Longniu ${ }^{\circledR}$ modelo GR-DB015 4 watts, CHN). Las luminarias fueron colocadas debajo de la parte superior de cada uno de los gabinetes de crecimiento. Se utilizaron dos perfiles por tratamiento (12 focos LED por perfil), los diferentes tratamientos de luz 
se describen en el Cuadro 1. La densidad de flujo de fotones

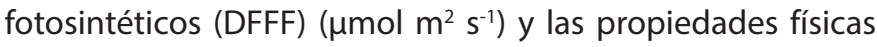
del espectro electromagnético de los tratamientos se midió con un espectroradiómetro (Apogee instruments ${ }^{\circledR}$ modelo SS-110, EUA) tomándose 124 mediciones del área de crecimiento de cada una de las unidades experimentales $(66 \mathrm{~cm} \times$ $20 \mathrm{~cm}=1320 \mathrm{~cm}^{2}$ ) (Cuadro 1).

Se realizó un análisis estadístico de las variables físicas de los tratamientos (Cuadro 1) para asegurar que las intensidades de luz entre tratamientos LED fueran iguales, las proporciones de luz azul y roja fueran diferentes, además de verificar el pico de longitud de onda (nm) e intervalo de la luz LED presente en los tratamientos. Se estableció un fotoperiodo para todos los tratamientos de luz de $15 \mathrm{~h}$ por día durante 48 días después de la siembra.

\section{Condiciones de crecimiento en la cámara de crecimiento}

A los siete días después de iniciar los tratamientos con luz, se ralearon las plantas para dejar tres plantas por contenedor. Los contenedores se regaron diariamente con 200 $\mathrm{mL}$ con la solución nutritiva de Hoagland (Hoagland y Arnon, 1950) al 50\% de concentración de los macronutrimentos con $\mathrm{pH}$ de 5.8 y CE de $1.33 \mathrm{dS} \mathrm{m}^{-1}$, los cuales se abastecieron con la mezcla comercial Tradecorp ${ }^{\otimes} \mathrm{AZ}\left(0.065 \mathrm{~g} \mathrm{~L}^{-1}\right)$. La temperatura ambiental promedio fue: día $24.2 \pm 0.1^{\circ} \mathrm{C} /$ noche $22.7 \pm 0.1$ ${ }^{\circ} \mathrm{C}$ y la humedad relativa promedio: día $62.1 \pm 0.2 \% /$ noche $83.3 \pm 0.3 \%$, se registró cada minuto la temperatura ambiental y la humedad relativa con el promedio de tres datalogger (Extech instruments ${ }^{\circledR}$ modelo RH10, USA), ubicados a nivel de copa de planta dentro de tres gabinetes seleccionados. La temperatura promedio de la solución nutritiva se midió con un termómetro infrarrojo (Extech instruments ${ }^{\circledR}$ modelo 42530, USA) y tuvo un valor de $21.8 \pm 0.1{ }^{\circ} \mathrm{C}$ y la concentración promedio de $\mathrm{CO}_{2}$ se midió en 4 momentos del día ( $7 \mathrm{am}$, $12 \mathrm{pm}, 17 \mathrm{pm}, 22 \mathrm{pm}$ ) con medidor portátil $\mathrm{CO}_{2}$ ambiental (Extech instruments ${ }^{\circledR}$ modelo CO250, USA) y fue de $378 \pm 53$ ppm.

\section{Variables de crecimiento de planta}

Después de 48 días con los tratamientos de luz LED las plantas se cosecharon y se determinó de la parte aérea: la altura de planta $(\mathrm{cm})$, peso fresco $\left(\mathrm{g} \mathrm{planta}^{-1}\right)$ con una balanza de precisión (Ohaus ${ }^{\circledR}$ Scout Pro, USA), número de hojas (planta) y el área foliar $\left(\mathrm{cm}^{2}\right.$ planta $\left.{ }^{-1}\right)$ con un integrador de área foliar (LICOR ${ }^{\oplus}$, modelo LI-3100, USA). Posteriormente, la parte aérea se secó en una estufa de aire forzado (BINDER ${ }^{\oplus}$ modelo FED $115, \mathrm{DEU}$ ) por 48 horas a $65^{\circ} \mathrm{C}$ y se registró el peso seco $\left(\mathrm{g} \mathrm{planta}^{-1}\right)$ con una balanza de precisión (Ohaus ${ }^{\circledR}$ Scout Pro, USA). A partir de estos datos se calculó el índice de área foliar con base en la fórmula [área foliar $\left(\mathrm{cm}^{2}\right) / a ́ r e a$ de cultivo $\left(\mathrm{cm}^{2}\right)$ ]. En cada una de las variables medidas se utilizaron cinco repeticiones por tratamiento.

\section{Concentración de pigmentos fotosintéticos}

Las concentraciones de clorofila $\mathrm{a}, \mathrm{b}$ y total $\left(\mathrm{mg} \mathrm{g}^{-1}\right.$ de peso fresco), proporción de clorofila a/b y concentración de carotenoides ( $\mathrm{mg} \mathrm{g}^{-1}$ de peso fresco) se determinaron mediante la metodología descrita por la AOAC (1980). Estas variables se determinaron en hojas frescas al momento de la cosecha. Se utilizaron tres repeticiones por tratamiento.

\section{Concentración nutrimental en la parte aérea}

Se determinaron $\mathrm{K}, \mathrm{P}, \mathrm{S}, \mathrm{Ca}, \mathrm{Mg}, \mathrm{Fe}, \mathrm{Mn}, \mathrm{Zn}$ y $\mathrm{Cu}$ en un espectrofotómetro de Emisión Atómica de Plasma por Inducción Acoplada (ICP-AES) (VARIAN modelo Liberty II, USA). La concentración de $\mathrm{N}$ se determinó con el método micro-Kjeldahl (Alcántar y Sandoval, 1999). Se utilizaron tres repeticiones por tratamiento.

\section{Diseño experimental y análisis estadístico}

El experimento se estableció en un diseño completamente al azar, una repetición estuvo constituida por un contenedor con tres plantas. Los datos se sometieron a un análisis de varianza (ANOVA) y a la prueba de comparación de medias de Tukey $(P<0.05)$ y a un análisis de ajuste a regresión polinomial de tercer grado mediante el programa SAS V9.0 (SAS Institute, 2002).

\section{RESULTADOS Y DISCUSIÓN}

\section{Variables de crecimiento}

Todos los parámetros de crecimiento evaluados se ajustaron a una regresión polinomial de tercer grado. La altura de planta fue mayor en tratamiento A0:R100, pero al incrementarse la proporción de luz azul se presentó una disminución constante hasta llegar a un valor mínimo con el tratamiento A74.2:R25.8 (Figura 1A). El peso fresco y seco de la parte aérea, área foliar e índice de área foliar mostraron un incremento conforme la proporción de luz azul aumentó a partir del tratamiento A0:R100 hasta llegar a los valores máximos con el tratamiento A37.7:R62.3; posteriormente, existió una disminución constante conforme la proporción de luz azul aumentó hasta llegar al $100 \%$ : con luz azul al $0 \%$ y 100 $\%$ se presentó el menor crecimiento (Figuras 1B, C, E y F).

El número de hojas por planta presentó un incremento a partir del tratamiento $\mathrm{A0}: \mathrm{R} 100$ hasta llegar al tratamiento A37.7:R62.3, posteriormente conforme la proporción de luz azul aumentó, el número de hojas disminuyó (Figura 1D).

Los resultados que registraron Yoneda et al. (2017) en plantas de stevia, tuvieron un comportamiento similar con lo obtenido en altura de planta de cilantro de nuestro experimento. El comportamiento de los resultados que se obtuvieron en peso fresco, peso seco y número de hojas de planta de cilantro coincidió con lo reportado por Chang et al. (2018) en plántulas de colza, además, los resultados que registraron Hernández et al. (2016) en plántulas de tomate, tuvieron un comportamiento similar con lo obtenido en peso seco y número de hojas de planta de cilantro en nuestro experimento.

Hernández y Kubota (2016) reportaron que el comportamiento de la altura, peso fresco, peso seco y área foliar de plántula de pepino, se ajustó a una regresión lineal, en donde existió una reducción de estas variables conforme existió un 

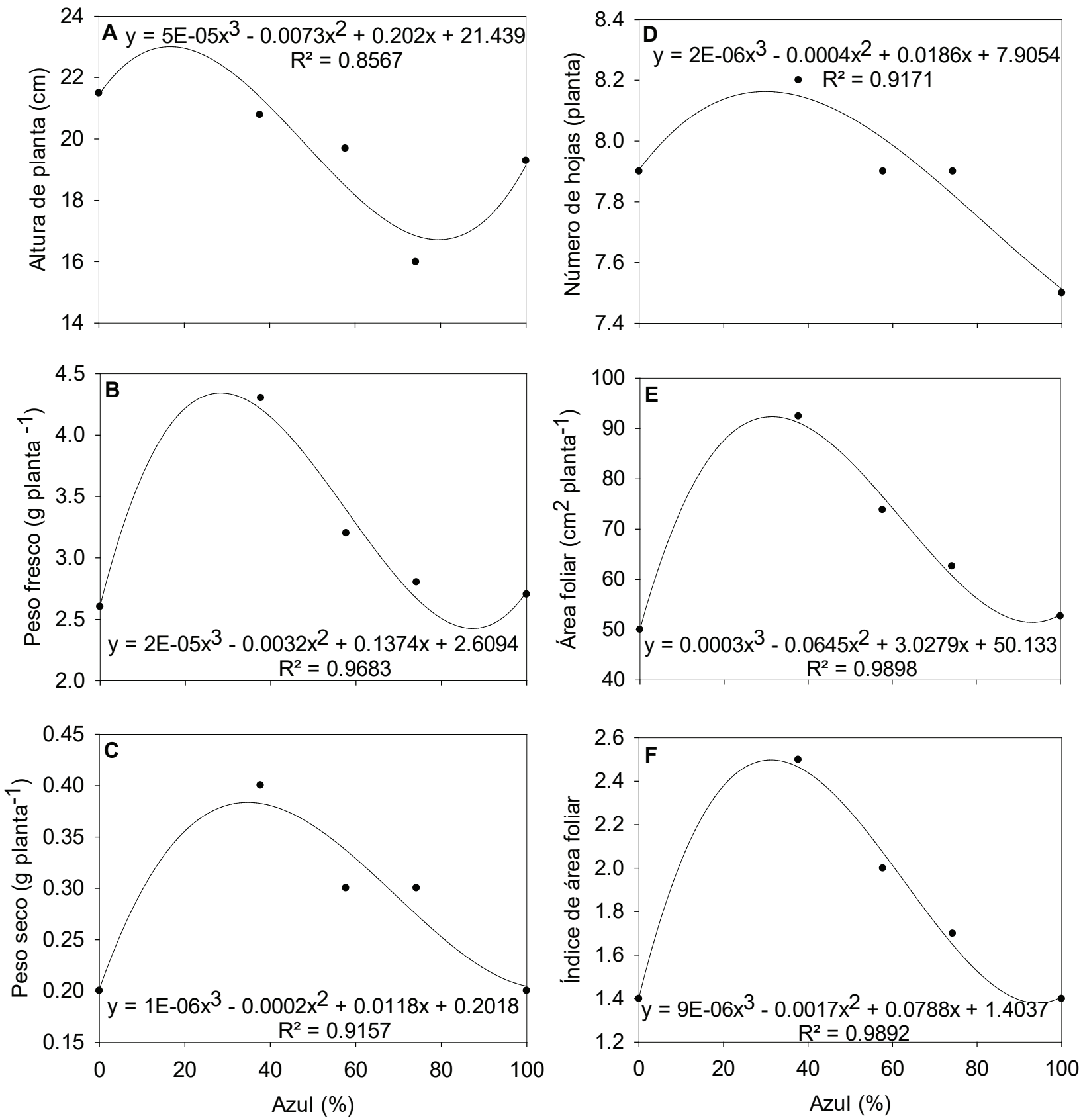

Figura 1. Efecto de la proporción de luz LED azul y roja en el crecimiento de cilantro 'Gladiador' cultivado bajo condiciones controladas con cinco diferentes tratamientos de luz LED: 0 \% azul:100 \% roja; $37.7 \%$ azul:62.3 \% roja; $57.7 \%$ azul:42.3 \% roja; $74.2 \%$ azul:25.8 \% roja; 100 \% azul:0 \% roja. La línea continua representa el ajuste de los resultados a una regresión polinomial de tercer grado.

Figure 1. Effect of the blue and red LED light ratio on growth of coriander 'Gladiador' grown under controlled conditions with five different LED light treatments: $0 \%$ blue: $100 \%$ red; $37.7 \%$ blue: $62.3 \%$ red; $57.7 \%$ blue: $42.3 \%$ red; $74.2 \%$ blue:25.8 \% red; $100 \%$ blue:0 \% red. The solid line represents the fit of the results to a third-degree polynomial regression.

mayor porcentaje de luz azul respecto al rojo en los tratamientos, por otro lado, también encontraron que diferentes proporciones de luz azul y roja no generaron efectos en el número de hojas en plántulas de pepino. Clavijo-Herrera et al. (2018) observaron que el comportamiento de los resultados de peso seco y área foliar de plantas de lechuga, se ajustaron a una regresión polinomial de segundo orden, en donde se registró una disminución del peso seco de plántula y un aumento en el área foliar conforme existió un mayor porcentaje de luz azul respecto al rojo en los tratamientos, donde se llegó, a un mínimo y a un máximo de valores de las variables evaluadas respectivamente, con un $60 \%$ de luz azul respecto al rojo y en donde a partir de ese punto, se volvió constante los resultados de las variables evaluadas, conforme la proporción de luz azul siguió su aumento; por otra parte, también encontraron que los resultados de número de hojas, se ajustaron a una regresión lineal, en donde a mayor proporción de luz azul respecto al rojo, se obtuvo menor 
número de hojas. Wollaeger y Runkle (2015) obtuvieron la mayor altura de plántula de tomate con un tratamiento de luz azul y roja A0:R100, sin embargo, el resto de tratamientos que evaluaron con diferentes porcentajes de luz azul $(6,13$ $25,50100 \%$ respecto al rojo, fueron menores y estadísticamente iguales entre ellos, también encontraron que el mayor peso fresco en plántulas de salvia y el área foliar de plántulas de impatiens y salvia, se ubicó en un tratamiento de luz azul y roja A0:R100, y conforme el porcentaje de luz azul respecto al rojo aumentó, el peso fresco y el área foliar disminuyó. Por otra parte, Agarwal et al. (2018) obtuvieron la mayor altura de planta de espinaca con un tratamiento de luz azul y roja A50:R50 y reportaron una disminución de altura, a partir de este tratamiento, conforme las proporciones de luz azul respecto al roja aumentaron y/o disminuyeron en los tratamientos restantes, y se registró que las plantas que tuvieron un tratamiento $A 0: R 100$ y A100:R0 presentaron la menor altura. Hong et al. (2015) evaluaron diferentes proporciones de luz azul y roja en plántulas de crisantemo y encontraron un comportamiento en donde el mayor peso fresco y seco se ubicó en el tratamiento A0:R100, y conforme el porcentaje de luz azul respecto al roja aumentó, el peso fresco y seco disminuyó. Por otro lado, Verma et al. (2018) evaluaron en plantas de Digitalis purpurea diferentes proporciones de luz azul y roja y obtuvieron el mayor número de hojas y área foliar con un tratamiento $A 20: R 80$, en donde en el resto de tratamientos evaluados (A0:R100, A50:R50, A80:R20 y A100:R0) tuvieron el menor número de hojas y área foliar. Yoneda et al. (2017) encontraron en plantas de stevia, una disminución del área foliar conforme la proporción de luz azul aumentó respecto a la roja. Por otra parte, Hernández et al. (2016) reportaron en plántulas de tomate la mayor área foliar con las combinaciones de luz azul y roja: A10:R90, A30:R70, A50:R50 y A75:R25, y de manera contraria la menor área foliar con los tratamientos A0:R100 y A100:R0.

Wollaeger y Runkle (2015) evaluaron tratamientos con diferentes proporciones de luz azul y roja, en los cuales encontraron que no se generaron efectos en la altura de plántulas de petunia, en el peso fresco de plántulas de tomate, en peso seco de plántulas de impatiens y petunia, en el número de hojas en plántulas de impatiens, salvia, tomate y petunia, y en el área foliar de plántulas de tomate. De manera similar, Hosseini et al. (2019) no encontraron efectos con diferentes tratamientos de luz azul y roja en el número de hojas en plantas de albahaca verde.

El comportamiento de los resultados obtenidos en este experimento, están basados en que la luz es la base del crecimiento, desarrollo y productividad de una planta, la cual, a través del aparato fotosintético, procesos bioquímicos dependientes de luz y diversos fotorreceptores, activan la expresión de genes de cloroplastos y núcleo, lo que genera la síntesis de compuestos y hormonas que en conjunto controlan el proceso completo de desarrollo de la planta (Berkovich et al., 2017). Por otra parte, se ha reportado que la luz roja tiende a promover en plantas la elongación del tallo, disminuye el número de hojas y aumenta la biomasa de la parte aérea, sin embargo, se ha observado que la luz azul puede tener la capacidad de aumentar o disminuir la longitud de la parte aérea de las plantas, área foliar y peso seco de la parte aérea, dependiendo de la especie y características del tratamiento de luz (Demotes-Mainard et al., 2016). Adicionalmente, la luz azul y roja también pueden inducir respuestas antagónicas entre estos en ciertos parámetros de crecimiento (Berkovich et al., 2017; Demotes-Mainard et al., 2016; Huché-Thélier et al., 2016).

Los resultados que se mencionaron de las anteriores investigaciones, se observó una diversidad de efectos que ejercen diferentes proporciones de luz azul y roja sobre las variables de crecimiento en diferentes especies de plantas, pero se encontró que muchos de los parámetros que se evaluaron tuvieron un tendencia de incrementar sus resultados conforme se aumentó el porcentaje de luz roja frente a la azul, esto puede deberse en parte, a que la luz roja es considerada como la longitud de onda más eficiente para la fotosíntesis en comparación con la luz azul, ya que la luz roja (600-700 nm) tiene una eficiencia cuántica mayor que la luz azul (400-500 nm) (McCree, 1972).

En nuestros resultados, lo anterior no se cumplió tal cual de esta manera, ya que los mayores valores se obtuvieron con un tratamiento de luz A37.7: R62.3, lo que puede deberse a característica inherente de la variedad y especie, que necesita tener un cierto porcentaje de luz azul para poder alcanzar los mejores rendimientos en crecimiento, debido a que para llevarse a cabo de manera más óptima el desarrollo de una planta es necesario tener tanto, por el aparato fotosintético y como por el sistema de fotoreceptores, la presencia de luz azul y roja (Pocock, 2015), ya que son las longitudes donde los pigmentos fotosintéticos tienen su punto máximo de absorción (clorofila a $662 \mathrm{~nm}$, clorofila b $642 \mathrm{~nm}$, carotenoides $450 \mathrm{~nm}$ y $480 \mathrm{~nm}$ ) (Blankenship, 2014) y los fotoreceptores (fitocromo: 350-800 nm, máxima absorción 660 y $730 \mathrm{~nm}$; criptocromo: $350-520 \mathrm{~nm}$, máxima absorción $365 \mathrm{~nm}, 445$ $\mathrm{nm}$; fototropina y proteínas ZEITLUPE: máxima absorción 450 nm) (Huché-Thélier et al., 2016).

Dadas las diferentes proporciones de luz azul y roja a las cuales las plantas fueron sometidas, estas poseen un alto grado de plasticidad en el proceso de aclimatación bajo diferentes condiciones de luz de su sistema de fotoreceptores, aparato fotosintético y procesos bioquímicos (Pocock, 2015).

Los resultados obtenidos en las variables de crecimiento en plantas de cilantro, al compararse con otros autores y con otros cultivos, reafirman que la composición espectral de la luz, así como la intensidad y el fotoperiodo, tienen un fuerte efecto de regulación en la morfogénesis de la planta, estado hormonal, ontogénesis y metabolismo secundario, así como la especie y el cultivar, lo que hace imposible proponer una recomendación universal para usar un parámetro de iluminación específico para cierto cultivo, lo cual coincide con lo señalado por Berkovich et al. (2017).

\section{Concentración de pigmentos fotosintéticos}

Existió un incremento en la de concentración clorofila 

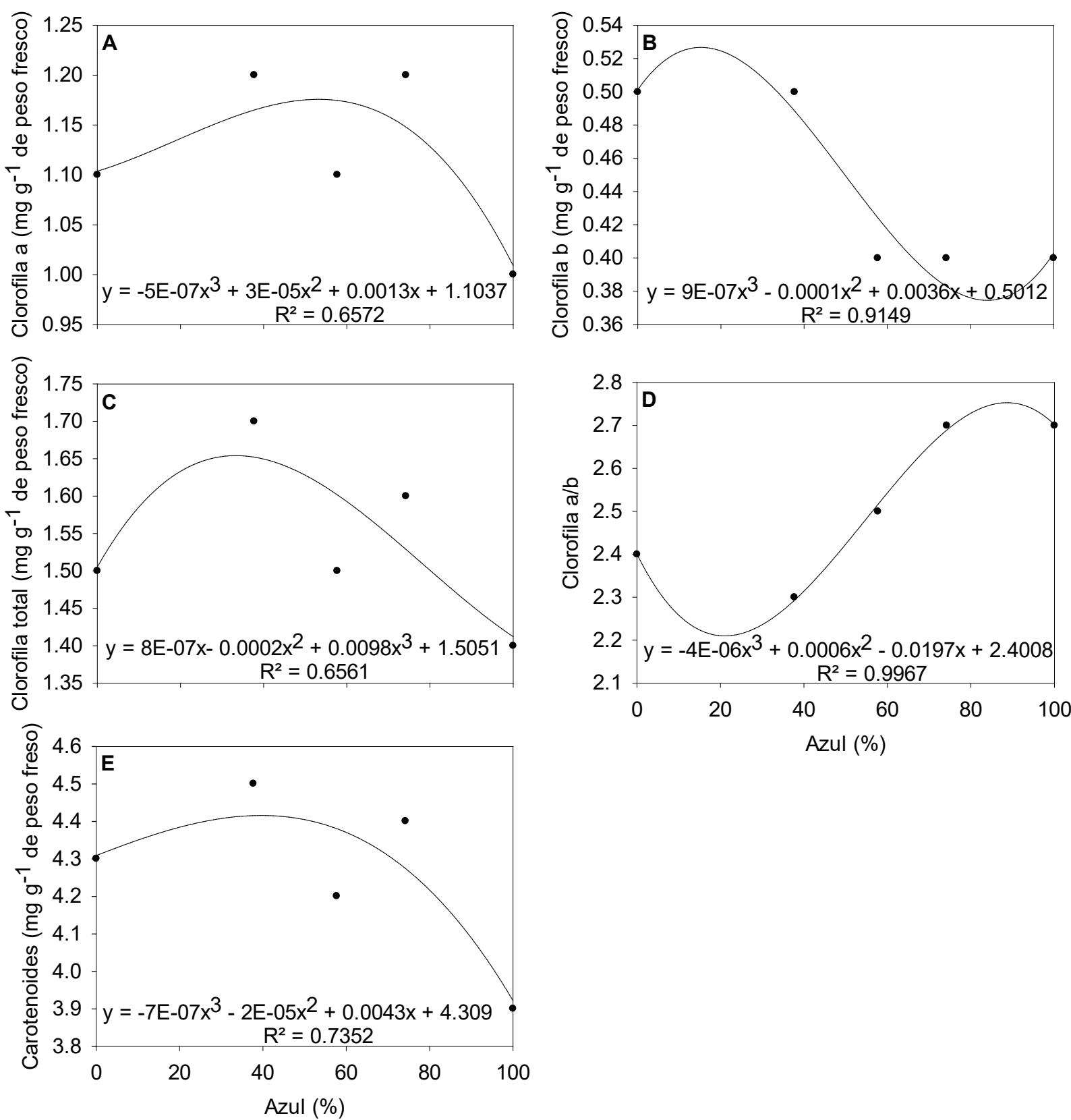

Figura 2. Efecto de la proporción de luz LED azul y roja en la concentración de pigmentos fotosintéticos en hojas de cilantro 'Gladiador' cultivado bajo condiciones controladas con cinco diferentes tratamientos de luz LED: $0 \%$ azul: $100 \%$ roja; $37.7 \%$ azul:62.3 \% roja; $57.7 \%$ azul:42.3 \% roja; $74.2 \%$ azul:25.8 \% roja; $100 \%$ azul:0 \% roja. La línea continua representa el ajuste de los resultados a una regresión polinomial de tercer grado.

Figure 2. Effect of the blue and red LED light ratio on photosynthetic pigments concentration in coriander leaves 'Gladiador' grown under controlled conditions with five different LED light treatments: $0 \%$ blue: $100 \%$ red; $37.7 \%$ blue:62.3 \% red; $57.7 \%$ blue:42.3 \% red; $74.2 \%$ blue: $25.8 \%$ red; $100 \%$ blue:0 \% red. The solid line represents the fit of the results to a third-degree polynomial regression.

a, total y carotenoides (Figuras $2 \mathrm{~A}, 2 \mathrm{C}$ y $2 \mathrm{E}$ ) a partir del tratamiento A0:R100 conforme la proporción de luz azul aumentó, hasta llegar a una máxima concentración en el tratamiento A37.7:R62.3; para el caso de la clorofila a, también lo fue con el tratamiento A74.2:R25.8.

La mayor concentración de clorofila b se detectó con el tratamiento A0:R100, así como en el tratamiento A37.7:R62.3 (Figura 2B), mientras que la relación clorofila a/b mostró un comportamiento opuesto (Figura 2D).

Los resultados de concentración de clorofila a, by total que registraron Hosseini et al. (2019) en plantas de albahaca verde, tuvieron un comportamiento similar en lo obtenido con los resultados de la presente investigación en plantas de cilantro, de manera similar, esto también se cumplió con los resultados de la concentración de clorofila total en plantas de espinaca que obtuvieron Agarwal et al. (2018). Hernández y Kubota (2016) reportaron que la concentración de clorofila total en plántula de pepino se ajustó a una regresión lineal, en donde a mayor porcentaje de luz azul respecto al rojo, se obtuvo mayor concentración de clorofila total. Hong et al. 
(2015) encontraron un comportamiento diferente en plántulas de crisantemo, en el cual los tratamientos de luz azul y roja A67:R33 y A100:R0, presentaron la mayor concentración de clorofila a y $b$, donde posteriormente existió a partir de estos una disminución conforme la proporción de luz azul respecto al rojo disminuyó en el resto de tratamientos.

Verma et al. (2018) observaron en plantas de Digitalis purpurea un comportamiento diferente en concentración de clorofila a y carotenoides, en donde la menor concentración de clorofila a se obtuvo por igual en los tratamientos A20:R80, A50:R50 y A80:R20, y a partir de estos tres tratamientos conforme la proporción de luz azul respecto al rojo aumentó y/o disminuyó en el resto de tratamientos que evaluaron, la concentración de clorofila a se incrementó; por otro lado, la mayor concentración de carotenoides se presentó en los tratamientos A80:R0 y A100:R0, y conforme la proporción de luz azul respecto al rojo disminuyó en el resto de tratamientos, la concentración de carotenoides disminuyó. Agarwal et al. (2018) encontraron en plantas de espinaca un comportamiento diferente en la concentración de carotenoides, ya que la mayor concentración se observó en un tratamiento con luz azul y roja A0:R100, en el cual, conforme la proporción de luz azul respecto al rojo aumentó en el resto de tratamientos, se generó una disminución de la concentración de carotenoides. Shengxin et al. (2016) obtuvieron un comportamiento diferente en la concentración de clorofila total, clorofila a/b y carotenoides en plántulas de colza, ya que la mayor concentración de clorofila total y carotenoides se ubicó en un tratamiento de luz azul y roja A75:R25, y a partir de este tratamiento se presentó una disminución en la concentración de clorofila total conforme la proporción de luz azul respecto a la roja aumentó y/o disminuyó en el resto de tratamientos, mientras que la relación de clorofila a/b de los tratamientos con luz azul y roja A25:R75, A50:R50, A75:R25 y A100:R0 presentaron la mayor relación de clorofila $\mathrm{a} / \mathrm{b}$, mientras que A0:R100 la menor relación. Hogewoning et al. (2010) encontraron en plántulas de pepino, que diferentes proporciones de luz azul y roja no generaron ningún efecto en la concentración de clorofila total en plántulas.

Los anteriores resultados se pueden explicar debido a que las plantas tienden a adaptar el contenido de clorofila al espectro de luz incidente; además, cuando está presente la luz azul con otras longitudes de onda, la clorofila total tiende a aumentar conforme la proporción de luz azul aumenta (Huché-Thélier et al., 2016). Adicionalmente, la relación clorofila a/b se incrementa independientemente de la especie, tanto con tratamientos monocromáticos azules, como con tratamientos donde existió un aumento de la proporción de luz azul (Huché-Thélier et al., 2016). Los carotenoides son pigmentos accesorios para absorber y transferir energía de la luz incidente (Blankenship, 2014), y tienden a aumentar en presencia de luz roja y disminuir con luz azul (Kubota, 2016), debido a que a través de estas dos longitudes de onda se induce la expresión de genes involucrados en la ruta de síntesis de carotenoides (Gupta y Pradhan, 2017).

\section{Concentración nutrimental en la parte aérea}

La concentración nutrimental se ajustó a una regresión polinomial de tercer grado para macronutrimentos $y$ micronutrimentos. En el caso del $\mathrm{N}$ y $\mathrm{Ca}$ (Figuras $3 \mathrm{~A}$ y $3 \mathrm{~B}$ ), estos disminuyeron a partir del tratamiento AO:R100 conforme la proporción de luz azul aumentó hasta llegar a alcanzar la concentración mínima con el tratamiento A37.7:R62.3, posteriormente existió un aumento en la concentración conforme la proporción de luz azul aumentó y se llegó a una concentración máxima en ambos elementos con el tratamiento A74.2:R25.8.

Por otro lado, la concentración de Mg y S (Figuras $3 \mathrm{C}$ y 3D) aumentaron a partir del tratamiento A0:R100 conforme la proporción de luz azul aumentó, hasta llegar en los tratamientos A57.7:R42.3 y A74.2:R25.8 en los que se registró la mayor concentración de ambos elementos; posteriormente disminuyó la concentración a partir del tratamiento A74.2:R25.8 hasta llegar al tratamiento A100:R0.

La concentración de P (Figura 3E) aumentó a partir del tratamiento $\mathrm{A0}: \mathrm{R} 100$ conforme la proporción de luz azul incrementó, hasta llegar al tratamiento A57.7:R42.3, en el cual se registró su máxima concentración, posteriormente existió una disminución de la concentración conforme la proporción de luz azul aumento hasta llegar al tratamiento A100:R0 donde se encontró la mínima concentración de P.

La concentración de $\mathrm{K}$ fue independiente de los tratamientos ya que no se ajustó los resultados a ningún otro modelo de regresión (Figura 3F). Verma et al. (2018) investigaron en Digitalis purpurea y encontraron que con una proporción de luz azul y roja de A80:R20, se presentó una mayor acumulación tanto de macronutrimentos $(\mathrm{P}, \mathrm{S}, \mathrm{Ca}, \mathrm{Mg})$ como de micronutrimentos ( $\mathrm{Fe}, \mathrm{Mn}, \mathrm{Zn}, \mathrm{B}, \mathrm{Cu}$ ). Lo anterior, coincidió con los resultados de $\mathrm{S}, \mathrm{Ca}, \mathrm{Mg}$ de la presente investigación.

La máxima concentración de Fe (Figura 4A) se registró en los tratamientos A0:R100 y A37.7:R62.3, a partir de los cuales existió una disminución conforme la proporción de luz aumentó hasta llegar al tratamiento A100:R0, en el que se registró la menor concentración. La máxima concentración de Zn (Figura 4B) se registró en el tratamiento A0:R100, donde posteriormente existió una disminución de concentración conforme la proporción de luz aumentó hasta llegar al tratamiento A100:R0 donde se obtuvo la mínima concentración de $\mathrm{Zn}$. La concentración de $\mathrm{Cu}$ en la parte aérea de cilantro (Figura 4C), tuvo un incremento a partir del tratamiento A0:R100 conforme la proporción de luz azul aumentó hasta llegar a un máximo de concentración en el tratamiento A57.7:R42.3, posteriormente existió una disminución de la concentración conforme la proporción de luz azul incrementó. El Mn (Figura 4D) registro su máxima concentración en el tratamiento $\mathrm{A0}: \mathrm{R} 100$, posteriormente se registró una disminución de concentración conforme la proporción de luz azul aumentó. Pennisi et al. (2019) usaron los tratamientos de luz roja y azul LED A19:R75, A23:R70, A30:R62, A44:R46, A58:R30 en albahaca y hallaron una tendencia clara donde el tratamiento A23:R70 fue el que permitió la mayor concentración de N, P, K, Ca, Mg y Fe; los resultados mencionados 

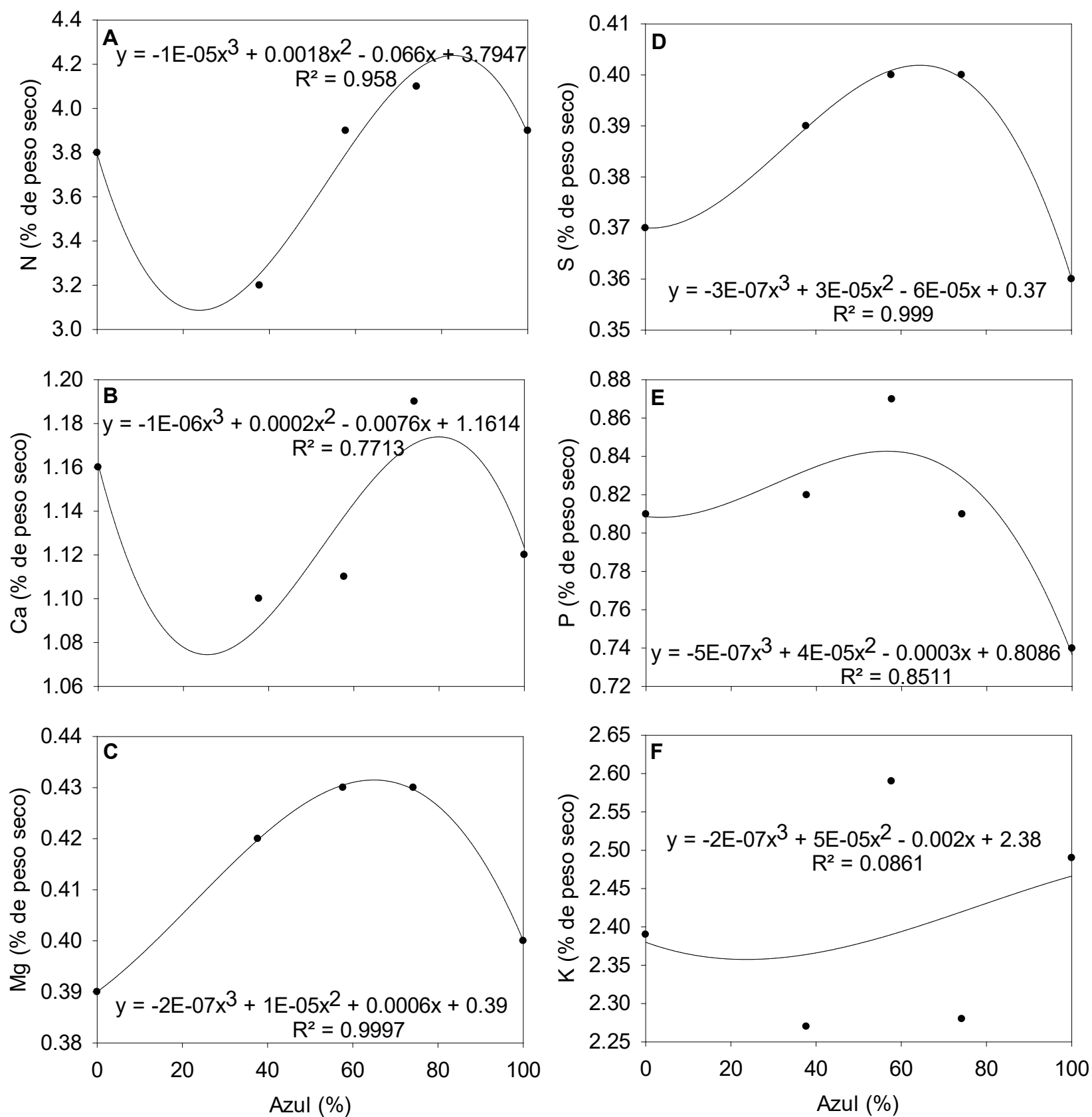

Figura 3. Efecto de la proporción de luz LED azul y roja en la concentración de macronutrimentos en cilantro 'Gladiador' cultivado bajo condiciones controladas con cinco diferentes tratamientos de luz LED: $0 \%$ azul:100 \% roja; $37.7 \%$ azul:62.3 \% roja; $57.7 \%$ azul:42.3 \% roja; $74.2 \%$ azul:25.8 \% roja; $100 \%$ azul:0 \% roja. La línea continua representa el ajuste de los resultados a una regresión polinomial de tercer grado.

Figure 3. Effect of the blue and red LED light ratio on macronutrient concentration in coriander 'Gladiador' grown under controlled conditions with five different LED light treatments: $0 \%$ blue: $100 \%$ red; $37.7 \%$ blue: $62.3 \%$ red; $57.7 \%$ blue: $42.3 \%$ red; $74.2 \%$ blue: $25.8 \%$ red; $100 \%$ blue: $0 \%$ red. The solid line represents the fit of the results to a third-degree polynomial regression.

anteriormente que encontraron Pennisi et al. (2019) se aproximaron un poco respecto a la concentración máxima de Fe que obtuvimos en nuestro experimento que se registró con el tratamiento A0:R100. Sakuraba y Yanagisawa (2018) mencionan que en Arabidopsis los mecanismos asociados a la absorción y asimilación del $\mathrm{N}$ en los tejidos es mediada por los fotorreceptores, fitocromos ( $\mathrm{A}$ y $\mathrm{B}$ ) asociados a luz roja y los criptocromos asociados a luz azul que se encuentran ubicados en la hoja, los cuales a su vez activan al promotor de transcripción HY5 (LONG HYPOCOTYL 5). Posteriormente este promotor se une y activa los genes codificadores de proteínas transportadoras de nitrato en raíz (familia NRT1 y NRT2) y de amonio (familia AMT1 y AMT2) y para la fase de asimilación del nitrato, el promotor HY5 cumple la función de activación y regulación de la expresión de los genes nitrato reductasa 2 (NIA2) y nitrito reductasa 1 (NIR1) que codifican para las enzimas nitrato reductasa y nitrito reductasa respectivamente (Gangappa y Botto, 2016) 
La asimilación del amonio en aminoácidos se lleva a cabo por las enzimas glutamina sintetasa (GS) y glutamato sintetasa (GOGAT) (Hawkesford et al., 2012). Miao et al. (2019) encontraron que la luz azul promovió la actividad de las enzimas GS y GOGAT, además se incrementó la absorción de nitrato y por consiguiente la concentración de N en planta. Se ha comprobado que la asimilación de nitrato y la biosíntesis de aminoácidos se incrementa con luz azul (Berkovich et al., 2017). Por otra parte, García-Caparrós et al. (2019) mencionan que la actividad de la enzima NR se incrementó en presencia de luz azul y también favoreció la acumulación de $\mathrm{N}$ en planta. Lo antes mencionado, coincidió con los resultados en concentración de $\mathrm{N}$, ya que a mayor proporción de luz azul se incrementó la concentración en planta (Figura 3).

La luz roja se ha asociado con la absorción y con el aumento en la concentración de P en Arabidopsis, debido al mecanismo asociado con el fotorreceptor fitocromo B en hoja, el cual media el proceso regulatorio de absorción y uso de $\mathrm{P}$ a través de dos vías de señalización y regulación, siendo la primera la vía-fitocromo B-HY5 y la segunda la vía-fitocromo B-PIFs (PHYTOCHROME INTERACTINF FACTOR), en donde en conjunto inducen en raíz la expresión del gen transportador de fosfato PHT1;1 (INORGANIC PHOSPHATE TRANSPORTER) y el gen PHL1 (HOMEODOMAIN-LIKE SUPERFAMILY PROTEIN) el cual también tiene la función de inducir la expresión del gen PHT1;1 (Sakuraba et al., 2018).

En los resultados que se obtuvieron de $\mathrm{P}$ en planta de cilantro (Figura 3) coincidió con lo mencionado por Sakuraba et al. (2018), ya que las plantas que recibieron solo luz azul presentaron una disminución de este nutrimento en comparación con las plantas que recibieron luz roja.

En plántulas de Arabidopsis la luz azul promueve la acumulación de $\mathrm{K}$ debido a una mayor actividad en el transporte de membrana asociados a los canales iónicos de $\mathrm{K}$ ubicados en las células guarda de los estomas (García-Caparrós et al., 2019). El comportamiento del K en el experimento no siguió una tendencia clara, lo que puedo deberse a un comportamiento propio de la especie, ya que fue el único macronutrimento que no se ajustó a la regresión polinomial de tercer grado. El mecanismo de absorción y asimilación de S (sulfato), se induce primero a través de una señal generada a nivel de fotorreceptores al recibir luz, la cual activa al promotor de transcripción HY5, el cual se une a determinados promotores de genes con lo cual se induce la síntesis y se aumenta la actividad del gen que codifica para la proteína transportadora de sulfato SULTUR1;2 (SULFATE TRANSPORTER 1;2) y de los genes APR1 (ADENOSINE 5'PHOSPHOSULPHATE REDUCTASE 1) y APR2 (ADENOSINE 5'PHOSPHOSULPHATE REDUCTASE 2) asociados con los mecanismos de asimilación (Gangappa y Botto, 2016; Sakuraba y Yanagisawa, 2018).

EI S forma parte de proteínas a través de los aminoácidos metionina y cisteína que poseen $\mathrm{S}$ en su estructura, forma parte también de la molécula glutatión, que es un antioxidante que protege a las células de especies reactivas de oxígeno, así como de otras moléculas involucradas en la defensa como glucosinolatos y tioredoxinas (Hawkesford et al., 2012).
En plantas de cilantro la mayor absorción de sulfato y posible asimilación en proteínas o moléculas asociadas al $\mathrm{S}$ fue mayor en plantas de cilantro que recibieron al mismo tiempo luz azul y roja (Figura 3). La luz azul induce en plantas de Arabidopsis la actividad de los transportadores de Ca (Kopsell et al., 2014) y también causa variaciones en el transporte iónico de membrana, asociado a Ca, en las células guarda de estomas (Kopsell y Sams, 2013), con lo cual puede inducir mayor acumulación en tejido.

El comportamiento de la concentración de Ca en plantas de cilantro coincidió con lo mencionado con los anteriores autores, sin embargo, en esta especie es necesario de un 25.8 \% de luz roja para obtener una máxima concentración en tejido (Figura 3). La concentración de Cu en cloroplastos, que es el orgánulo donde existe la mayor concentración, se modula mediante el mecanismo asociado con el promotor de transcripción HY5, el cual previamente se activa a través de una cascada de señalización intercelular generada por los fotorreceptores que son activados por el tipo de longitud de onda asociado a éstos, posteriormente el promotor HY5 cumple la función de interactuar físicamente con el factor de transcripción SPL7 (SQUAMOSA PROMOTER-BINDING PROTEIN-LIKE 7), los en conjunto activan el gen MIR408 (microRNA408) que es requerido para regular la expresión de los genes PETE1 (PLASTOCYANIN 1) y PETE2 (PLASOCYANIN 2) los cuales son los encargados de la síntesis de proteína plastocianina en cloroplasto y que contiene $\mathrm{Cu}$ en su estructura (Gangappa y Botto, 2016; Sakuraba y Yanagisawa, 2018).

En plantas de cilantro existió una posible mayor concentración $\mathrm{Cu}$ relacionado a la proteína plastocianina, cuando los tratamientos tuvieron una aproximación de una proporción de luz azul y roja $\approx 1: 1$, la cual se registró en las plantas que recibieron $57.7 \%$ de luz azul (Figura 4). Miao et al. (2019) mencionan que existe una mayor concentración de Zn y $\mathrm{Mn}$ en la presencia de luz roja. Este comportamiento se observó en Zn, ya que las plantas con tratamientos que tuvieron luz roja fueron mayores a las plantas que solo recibieron luz azul. De manera similar, el Mn presentó una evidente mayor concentración en planta bajo la presencia de solo luz roja respecto al resto de tratamientos (Figura 4).

De manera general la concentración de nutrimentos en plantas puede verse afectada a través de procesos fisiológicos como apertura estomática, transpiración, biomasa acumulada, y tasa de crecimiento (Metallo et al., 2018). Se ha asociado que la luz roja promueve la acumulación de micronutrimentos en tejido Miao et al. (2019). Por otro lado, la luz azul se ha corroborado que puede aumentar de manera general la concentración de macronutrimentos y micronutrimentos dependiendo de la especie y la etapa de crecimiento, a través de una mayor apertura estomática, un incremento en la permeabilidad de los canales iónicos asociados a la absorción de nutrimentos y junto con un aumento en la tasa de transpiración (Brazaitytè et al., 2018; Craver et al., 2018; Gerovac et al., 2016). Se requiere de mayor investigación para conocer más sobre los mecanismos y vías de señalización involucrados en la absorción y asimilación de nutrimentos bajo el efecto de diferentes tipos de longitud de onda (Amoozgar et al., 2017; Miao et al., 2019). 

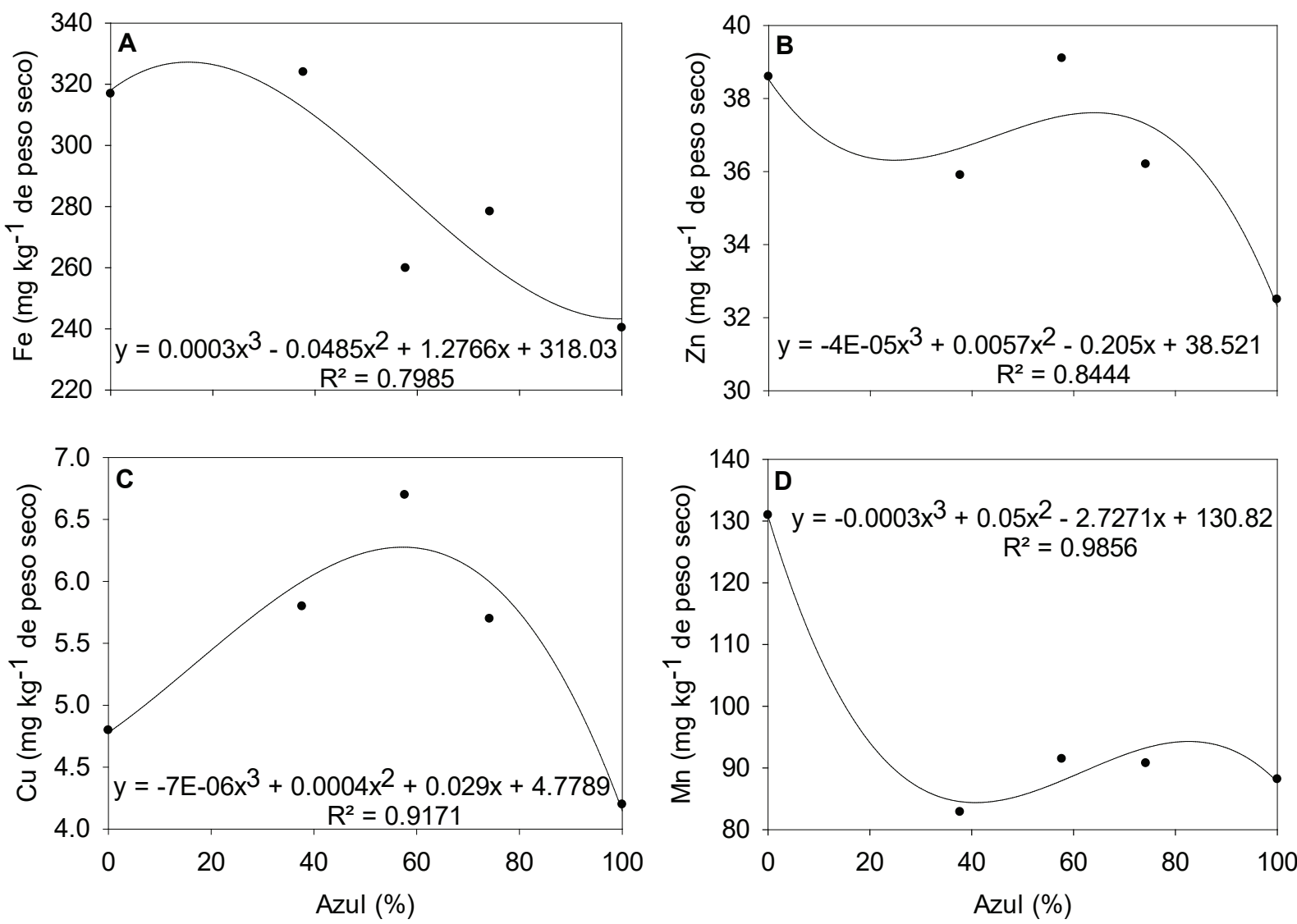

Figura 4. Efecto de la proporción de luz LED azul y roja en la concentración de micronutrimentos en cilantro 'Gladiador' cultivado bajo condiciones controladas con cinco diferentes tratamientos de luz LED: $0 \%$ azul:100 \% roja; $37.7 \%$ azul:62.3 \% roja; $57.7 \%$ azul:42.3 \% roja; 74.2 $\%$ azul:25.8 \% roja; $100 \%$ azul:0 \% roja. La línea continua representa el ajuste de los resultados a una regresión polinomial de tercer grado. Figure 4. Effect of the blue and red LED light ratio on micronutrient concentration in coriander 'Gladiador' grown under controlled conditions with five different LED light treatments: $0 \%$ blue: $100 \%$ red; $37.7 \%$ blue:62.3 \% red; $57.7 \%$ blue: $42.3 \%$ red; $74.2 \%$ blue: $25.8 \%$ red; 100 $\%$ blue: $0 \%$ red. The solid line represents the fit of the results to a third-degree polynomial regression.

\section{CONCLUSIONES}

La relación de luz azul y roja A37.7:R62.3 promovió el crecimiento y concentración de pigmentos fotosintéticos, mientras que una proporción de luz azul y roja A57.7:R42.3 promovió la concentración nutrimental en la parte aérea de cilantro. Lo anterior permite deducir que, para una posible producción comercial de cilantro, en condiciones de ambiente controlado, la mejor relación de luz azul y roja es A37.7:R62.3 ya que se promueve el crecimiento y por lo tanto el rendimiento comercial.

\section{REFERENCIAS}

Amoozgar, A., Mohammadi, A. y Sabzalian, M.R. 2017. Impact of light-emitting diode irradiation on the photosynthesis, phytochemical composition and mineral element content of lettuce cv. Grizzly. Photosynthetica. 55: 85-95. https://doi. org/ 10.1007/s11099-016-0216-8.

Alcántar, G. y Sandoval, M. 1999. Manual de análisis químico de tejido vegetal. Publicación especial 10. Sociedad Mexicana de la Ciencia del Suelo, A. C. Estado de México, México.

Alvarez-Carvajal, F., Gonzalez-Soto, T., Armenta-Calderón, A.D., Méndez-lbarra, R., Esquer-Miranda, E., Juarez, J. y Encinas-
Basurto, D. 2020. Silver nanoparticles coated with chitosan against Fusarium oxysporum causing the tomato wilt. Biotecnia. 22(3): 73-80. https://doi.org/10.18633/biotecnia. v22i3.952.

Agarwal, A., Gupta, S.D., Barman, M. y Mitra, A. 2018. Photosynthetic apparatus plays a central role in photosensitive physiological acclimations affecting spinach (Spinacia oleracea L.) growth in response to blue and red photon flux ratios. Environmental and Experimental Botany. 156: 170-182. https://doi.org/10.1016/j. envexpbot.2018.09.009.

AOAC. 1980. Official methods of analysis. 12th ed. Association of Official Analytical Chemistry. Washington, D.C.

Clarenc-Aarland, R., Castellanos-Hernández, O.A., RodríguezSahagún, A. y Acevedo-Hernández, G.J. 2020. Efecto del estrés salino sobre la morfología y fitoquímica de orégano mexicano (Lippia graveolens Kunth) cultivado in vitro. Biotecnia. 22(3): 131-137. https://doi.org/10.18633/ biotecnia.v22i3.1223.

Craver, J.K., Boldt, J.K. y Lopez, R.G. 2018. Radiation intensity and quality from sole-source light-emitting diodes affect seedling quality and subsequent flowering of long-day bedding plant species. HortScience, 53(10): 1407-1415. https://dx.doi.org/ 10.21273/HORTSCI13228-18. 
Berkovich, Y.A., Konovalova, I.O., Smolyanina, S.O., Erokhin, A.N., Avercheva, O.V., Bassarskaya, E.M., Kochetova, G.V., Zhigalova, T.V., Yakovleva, O.S. y Tarakanov, I.G. 2017. LED crop illumination inside space greenhouses. REACH Reviews in Human Space Exploration. 6: 11-24. http://dx.doi. org/10.1016/j.reach.2017.06.001.

Blankenship, R.E.2014. Molecularmechanisms of photosynthesis. 2nd ed. Wiley Blackwell. New Delhi, India.

Brazaitytè, A., Vaštakaitè, V., Viršilè, A., Jankauskienė, J., Samuolienè, G., Sakalauskienè, S., Novičkovas, A., Miliauskienè, J. y Duchovskis, P. 2018. Changes in mineral element content of microgreens cultivated under different lighting conditions in a greenhouse. Acta Horticulturae. 1227. https://doi.org/10.17660/ActaHortic.2018.1227.64.

Chang, S., Pu, C., Guan, R., Pu, M. y Xu, Z. 2018.Transcriptional and translational responses of rapeseed leaves to red and blue lights at the rosette stage. Journal of Zhejiang University-SCIENCE B. 19: 581-595. https://doi.org/10.1631/ jzus.B1700408.

Clavijo-Herrera, J., van Santen, E. y Gómez, C. 2018. Growth, Water-Use Efficiency, Stomatal Conductance, and Nitrogen Uptake of Two Lettuce Cultivars Grown under Different Percentages of Blue and Red Light. Horticulturae. 4(3): 16. https://doi.org/10.3390/horticulturae4030016.

Demotes-Mainard, S., Pérona, T., Corotb, A., Bertheloota, J., Gourrierecb, J.L., Pelleschi-Travierb, S., Crespel, L., Morel, P., Huché-Thélier, L., Boumaza, R., Vian, A., Guérin, V., Leduc, N. y Sakr, S. 2016. Plant responses to red and far-red lights, applications in horticulture. Environmental and Experimental Botany. 121: 4-21. http://dx.doi.org/10.1016/j. envexpbot.2015.05.010.

Gangappa, S.N. y Botto, J.F. 2016. The multifaceted roles of hy5 in plant growth and development. Molecular Plant. 9: 1353-1365. https://dx.doi.org/10.1016/j.molp.2016.07.002

García-Caparrós, P., Almansa, E.M., Chica, R.M. y Lao, M.T. 2019. Effects of artificial light treatments on growth, mineral composition, physiology, and pigment concentration in Dieffenbachia maculate "Compacta" plants. Sustainability. 11: 2867. https://dx.doi.org/10.3390/su11102867.

Gerovac, J.R., Craver, J.K., Boldt, J.K. y Lopez, R.G. 2016. Light intensity and quality from sole-source light-emitting diodes impact growth, morphology, and nutrient content of Brassica microgreens. HortScience. 51(5): 497-503. https:// doi.org/10.21273/HORTSCI.51.5.497.

Gupta, S. D. y Pradhan, S. 2017. Regulation of gene expression by LED lighting. En: Light Emitting Diodes for Agriculture. S. D. Gupta (ed.), pp 237-258. Springer Nature Singapore, Singapore. https://doi.org/ 10.1007/978-981-10-5807-3_10.

Hawkesford, M., Horst, W., Kichey, T., Lambers, H., Schjoerring, J., Moller, I. S. y White, P. 2012. Functions of macronutrients. En: Marschner's Mineral Nutrition of Higher Plants. P. Marschner (ed.), pp 135-189. Academic Press, USA. https://dx.doi. org/10.1016/B978-0-12-384905-2.00006-6.

Hernández, R., Eguchib, T., Devecic, M. y Kubota, C. 2016. Tomato seedling physiological responses under different percentages of blue and red photon flux ratios using LEDs and cool white fluorescent lamps. Scientia Horticulturae. 213: 270-280. http://dx.doi.org/10.1016/j.scienta.2016.11.005.

Hernández, R. y Kubota, C. 2016. Physiological responses of cucumber seedlings under different blue and red photon flux ratios using LEDs. Environmental and Experimental
Botany. 121: 66-74. http://dx.doi.org/10.1016/j. envexpbot.2015.04.001.

Hoagland, D.R. y Arnon, D.I. 1950. The water-culture method for growing plants without soil. Circular 347. California Agricultural Experiment Station. California, USA.

Hogewoning, S.W., Trouwborst, G., Maljaars, H., Poorter, H., van leperen, W. y Harbinson, J. 2010. Blue light dose-responses of leaf photosynthesis, morphology, and chemical composition of Cucumis sativus grown under different combinations of red and blue light. Journal of Experimental Botany. 61(11): 3107-3117. http://dx.doi.org/10.1093/jxb/erq132.

Hong, Y., Huang, H. y Dai, S. 2015. An in vivo study of the best light emitting diode (LED) systems for cut chrysanthemums. Open Life Sciences. 10: 310-321. https://doi.org/ 10.1515/ biol-2015-0031.

Hosseini, A., Mehrjerdi, M.Z., Aliniaeifard, S. y Seif, M. 2019. Photosynthetic and growth responses of green and purple basil plants under different spectral compositions. Physiology and Molecular Biology of Plants.25:741-752. https://doi.org/10.1007/s12298-019-00647-7.

Huché-Thélier, L., Crespel, L., Gourrierec, J.L., Morel, P., Sakr, S. y Leduc, N. 2016. Light signaling and plant responses to blue and UV radiations-Perspectives for applications in horticulture. Environmental and Experimental Botany. 121: 22-38. https://dx.doi.org/10.1016/j.envexpbot.2015.06.009.

Katagiri, F., Canelon-Suarez, D., Griffin, K., Petersen, J., Meyer, R.K. y Siegle, M. 2015. Design and construction of an inexpensive homemade plant growth chamber. PLOS ONE. 10(5): e0126826. https://doi.org/10.1371/journal.pone.0126826.

Kopsell, D. A. y Sams, C. E. 2013. Increases in shoot tissue pigments, glucosinolates, and mineral elements in sprouting broccoli after exposure to short-duration blue light from light emitting diodes. Journal of the American Society for Horticultural Science. 138(1): 31-37. https://doi. org/10.21273/JASHS.138.1.31.

Kopsell, D. A., Sams, C. E., Barickman, T. C. y Morrow, R. C. 2014. Sprouting broccoli accumulate higher concentrations of nutritionally important metabolites under narrow-band light-emitting diode lighting. Journal of the American Society for Horticultural Science. 139(4): 469-477. https:// doi.org/10.21273/JASHS.139.4.469.

Kozai, T. y Niu, G. 2016. Role of the plant factory with artificial lighting (PFAL) in urban areas. En: Plant factory: An indoor vertical farming system for efficient quality food production. T. Kozai, G. Niu y M. Takagaki (ed.), pp 115-128. Academic Press, USA. https://dx.doi.org/10.1016/B978-0-12-8017753.00002-0.

Kubota, C. 2016. Growth, development, transpiration and translocation as affected by abiotic environmental factors. En: Plant factory: An indoor vertical farming system for efficient quality food production. T. Kozai, G. Niu y M. Takagaki (ed.), pp 151-164. Academic Press, USA. http:// dx.doi.org/10.1016/B978-0-12-801775-3.00010-X.

Laribi, B., Kouki, K., M'Hamdi, M. y Bettaieba, T. 2015. Coriander (Coriandrum sativum L.) and its bioactive constituents. Fitoterapia. 103: 9-26. http://dx.doi.org/10.1016/j. fitote.2015.03.012.

Mahendra, P. y Bisht, S. 2011. Coriandrum sativum: A daily use spice with great medicinal effect. Pharmacognosy Journal. 3(21): 84-88. http://dx.doi.org/10.5530/pj.2011.21.16. 
Márquez-Reyes, J.M., Valdés-González, A., García-Gómez, C., Rodríguez-Fuentes, H., Gamboa- Delgado, J. y Luna-Olvera, H. 2020. Evaluación de los efectos sinérgicos de cromo y plomo durante el proceso de fitorremediación con berro (Nasturtium officinale) en un humedal artificial. Biotecnia. 22(2): 171-178. https://doi.org/10.18633/biotecnia. v22i2.1259.

McCree, K.J. 1972. The action spectrum, absorptance and quantum yield of photosynthesis in crop plants. Agricultural Meteorology. 9: 191-216. https://doi.org/10.1016/00021571(71)90022-7.

Metallo, R. M., Kopsell, D. A., Sams, C. E. y Bumgarner, N. R. 2018. Influence of blue/red vs. white LED light treatments on biomass, shoot morphology, and quality parameters of hydroponically grown kale. Scientia Horticulturae. 235: 189197. https://doi.org/10.1016/j.scienta.2018.02.061

Miao, Y., Chen, Q., Qu, M., Gao, L. y Hou, L. 2019. Blue light alleviates 'red light syndrome' by regulating chloroplast ultrastructure, photosynthetic traits and nutrient accumulation in cucumber. Scientia Horticulturae. 257: 108680. https://doi.org/10.1016/j.scienta.2019.108680

Naznin, M.T., Lefsrud, M., Gravel,V., \&Hao, X. (2016).Different ratios of red and blue LED light effects on coriander productivity and antioxidant properties. Acta Horticulturae. 1134: 223230. https:// dx.doi.org/10.17660/ActaHortic.2016.1134.30

Nguyen, D. T. P., Lu, N., Kagawa N. y Takagaki, M. 2019. Optimization of photosynthetic photon flux density and root-zone temperature for enhancing secondary metabolite accumulation and production of coriander in plant factory. Agronomy. 9(5): 224. https://doi.org/10.3390/ agronomy9050224.

Pennisi, G., Blasioli, S., Cellini, A., Maia, L., Crepaldi, A., Braschi, I., Spinelli, F., Nicola, S., Fernandez, J.A., Stanghellini, C., Marcelis, L.F.M., Orsini, F. y Gianquinto, G. 2019. Unraveling the role of red:blue LED lights on resource use efficiency and nutritional properties of indoor grown sweet basil. Frontiers in Plant Science. 10: 305. https://doi.org/10.3389/ fpls.2019.00305

Pocock, T. 2015. Light-emitting diodes and the modulation of specialty crops: light sensing and signaling networks in plants. HortScience. 50(9): 1281-1284. https://dx.doi. org/10.21273/HORTSCl.50.9.1281.
Prachayasittikul, V., Prachayasittikul, S., Ruchirawat, S. y Prachayasittikule, V. 2018. Coriander (Coriandrum sativum): A promising functional food toward the well-being. Food Research International. 105: 305-323. https://doi. org/10.1016/j.foodres.2017.11.019.

Sakuraba, Y., Kanno, S., Mabuchi, A., Monda, K., Iba, K. y Yanagisawa, S. 2018. A phytochrome-B-mediated regulatory mechanism of phosphorus acquisition. Nature plants. 4: 1089-1101. https://dx.doi.org/10.1038/s41477-018-0294-7.

Sakuraba, Y. y Yanagisawa, S. 2018. Light signalling-induced regulation of nutrient acquisition and utilisation in plants. Seminars in Cell \& Developmental Biology. 83: 123-132. https://doi.org/10.1016/j.semcdb.2017.12.014.

SAS Institute (2002) SAS System for Windows Computer Program. Software Version 9.0. Cary, North Carolina, USA.

Shengxin, C., Chunxia, L., Xuyang, Y., Song, C., Xuelei, J., Xiaoying, L., Zhigang, X. y Rongzhan, G. 2016. Morphological, photosynthetic, and physiological responses of rapeseed leaf to different combinations of red and blue lights at the rosette stage. Frontiers in Plant Science. 7: 1144. https://doi. org/10.3389/fpls.2016.01144.

Verma, S.K., Gantait, S., Jeong, B.R. y Hwang, S.J. 2018. Enhanced growth and cardenolides production in Digitalis purpurea under the influence of different LED exposures in the plant factory. Nature Scientific Reports. 8: 18009. https://doi. org/10.1038/s41598-018-36113-9.

Wei, J-N., Liu, Z-H., Zhao, Y-P., Zhao, L-L., Xue, T-K. y Lan, Q-K. 2019. Phytochemical and bioactive profile of Coriandrum sativum L. Food Chemistry. 286: 260-267. https://doi.org/10.1016/j. foodchem.2019.01.171.

Yoneda, Y., Nakashima, H., Miyasaka, J., Ohdoi, K. y Shimizu, H. 2017. Impact of blue, red, and far-red light treatments on gene expression and steviol glycoside accumulation in Stevia rebaudiana. Phytochemistry. 137: 57-65. https://doi. org/10.1016/j.phytochem.2017.02.002.

Viršilè, A., Olle M. y Duchovskis, P. 2017. LED Lighting in Horticulture. En: Light Emitting Diodes for Agriculture. S.D. Gupta (ed.), pp 113-147. Springer Nature Singapore, Singapore. https://doi.org/10.1007/978-981-10-5807-3_7.

Wollaeger, H.M. y Runkle, E.S. 2015. Growth and acclimation of impatiens, salvia, petunia, and tomato seedlings to blue and red light. HortScience. 50(4): 522-529. https://doi. org/10.21273/HORTSCl.50.4.522. 